\title{
HOW DATA ANALYTICS HELPS MANAGEMENT IN GLOBAL PANDEMIC SITUATION
}

\author{
Dimitar Dimitrov ${ }^{1}$ \\ Radko Radev ${ }^{2}$
}

DOI: https://doi.org/10.31410/ITEMA.2020.209

\begin{abstract}
The ongoing COVID-19 pandemic is having a tremendous impact on the business organizations, governments and people around the Globe. No matter if it is a public, or private organization, the leaders and management have changed their approaches, standard operations, the way they communicate, processes and procedures. In this paper is analyzed the impact of Data Analytics on two main management pillars and more specifically: Business Operations and Human Resources Management; more precisely, how they are impacted and changed in the pandemics. We analyzed how Global IT Companies are reacting and using analytics as a tool that helps them in the day to day operations, representing some used models and patterns.
\end{abstract}

Keywords: Management, Corporate management, Data analysis.

\section{INTRODUCTION}

\section{COVID-19 outbreak}

$\mathrm{D}$ ecember $31^{\text {st }}$, the World Health Organization (WHO) reports "Pneumonia of unknown cause", detected in Hubei province in the city of Wuhan, China. This is how everything started at the close of 2019. The novel Coronavirus started with officially reported 44 cases in January 2020, out of which 11 severely ill and remaining 33 in "stable condition", WHO $(1,2020$, July 30).

Eight months later (as of end of July 2020) initially reported few cases in the China province became the fastest spreading world-wide virus declared by WHO as a pandemic situation.

The latest numbers are as follows WHO (2020, July 30):

- 33,502,430 Total Cases (total cumulative count). The number include deaths, recovered and discharged patients;

- $\mathbf{2 . 9 \%}$ reported deaths, calculated on the base of 1,004,421 deaths;

- $\mathbf{5 , 7 5 7 , 8 5 9}$ Currently infected, of which $~ 99 \%(5,691,295)$ defined as mid-condition and $\sim 1 \%(66,564)$ as serious or critical cases;

- $\quad 0.5 \%(83,959)$ of the cases are from China Mainland and $29.5 \%(16,566,611)$ from other countries. At this point of time the most impacted countries are as follows: United States 26,63\% (4,433,410), Brazil 14,69\% (2,446,397), India 8.91\% (1,484, 136), Russia $4,91 \%(818,120)$, South Africa 2,72\% (452,592);

- Total Cured 10,226,484 (Includes recovered and Discharged);

- Total Critical and Serious cases fluctuates between 40,000 (beginning of April) to 66,564 (end of July) which is the biggest absolute number since the beginning. 
All these facts indicate a massive impact which goes beyond a single country or continent, small, medium or big corporation, or a single industry. Pandemic affected not only private companies and business owners but as well governments, non-profit organizations and people`s lives.

It is no surprise that COVID-19 impacted every element in the macro-environment map: Political, Economic, Social, Technological, Environmental and Legal (PESTEL). Companies needed to change and adapt their operations, and the IT industry was not an exception. Global players had maybe a benefit of having a world-wide footprint which enabled them to be more flexible, but the local companies needed to act locally and be innovative in order to survive.

\section{Data analysis}

So called Data Analytics 2.0 came in the mid-2000's when social network firms and internetbased companies like eBay, Google and Facebook started to collect and analyze new and extremely large volumes of data. The data was not only companies' internal data, but it has external sources as well e.g. sensors, internet, public data, audio and video.

With all this dramatic change, this phase raised the requirements for new more powerful tools and the opportunity was used by some companies to materialize and profit it. New products, skills, expertise and professions emerged out the new requirements and market. Hadoop, NoSQL, Apache Spark and many other solutions were started to be developed. Terms like Machine-learning and Artificial Inelegance started to form a real added value for the business.

In the 2.0 phase some very prominent observers have seen the beginning of the next phase (3, Thomas H. Davenport, 2013) which is described with not only further development of the products, service and features but when the large companies which are not just Internet and IT Companies started to adopt above principles to create new products and services in their industries.

From another angle, next to the three eras analytics can be defined by its type and capabilities:

1. Descriptive - "What happed?"

Descriptive analytics is used to describe and explain different relationships between various sources usually within the existing big data bases.

2. Diagnostic - "Why did it happen?"

As the name dictates Diagnostic Analytics gives answer on "Why this happen" question. It focuses on the root cause analysis investigating the sources, factors and causes of the results.

3. Predictive - "What will happen?"

Predictive analytics focuses on solving problems coming from forecasting and trends analysis. It gives answers and predicts future again based on sets of data and applying metaethical models.

4. Prescriptive - "What should be done"

The logical sequence is prescription of the actions which needs to be taken in every individual case after analyzing what and why happened. This part of data analytics steps on the Predictive Analytics and uses very specific knowledge algorithms for every entity, organization or company. It might consist of Artificial Intelligence (AI) or Machine Learning algorithms or Data Driven Decision Making System. It usually provides 
scenarios and based on the specific case it might be applied automatically or be suggested to respective management function which needs to take decision and act.

In the current global pandemic situation, the use of Data Analytics can be vital for organizations. Analytics can give quick answers to complex questions combining various, on the first look not connected data sources which cannot be analyzed with conventional methods and tools. It is also purely data driven, which means that in such unknown situations like the COVID-19 pandemic it is driven mainly from facts and data leaving emotions and legacy aside.

The other main advantage is that Big Data analytics can combine various sources of large unstructured data, combine and relate them providing trends and suggestions which might be totally radical or illogical and which might give competitive advantage for the organization.

\section{Management reaction}

Economic impact was dramatic world-wide. After the pandemic spread, and the governments started implementing measures and restrictions, the impact on business was inevitable. GDP and economic forecasts collapsed all around. We have seen the majority of the biggest economies in the world reporting forecasts for more than -3\% drop (USA, Germany, France, UK etc.). One of the biggest economic drivers like India and China report positive numbers $+1.2 \%$ and $+1.9 \%$, which compared to their usual growth seems like recession.

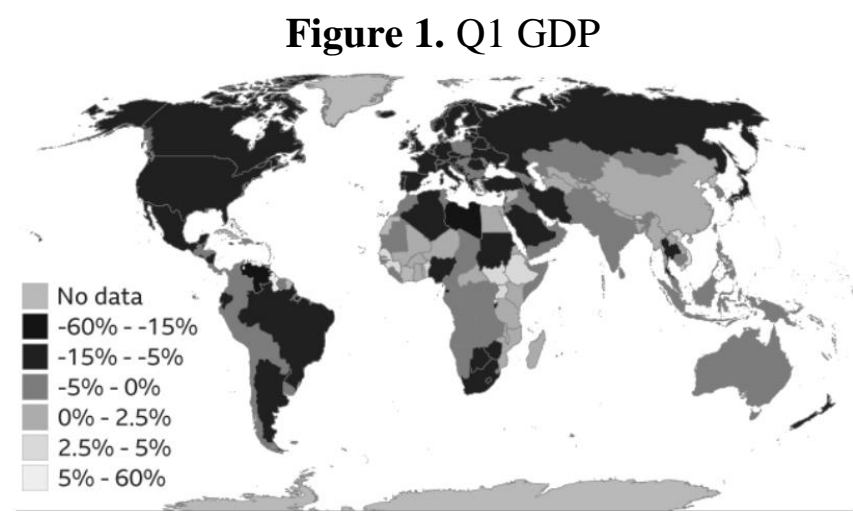

Source: 4, Lora Jones, Palumbo and Brown, 2020

Another major factor for the impact on the global economy is stock markets reactions. Figure 2 (4, Lora Jones, Palumbo and Brown 2020) shows how the three main stock indexes plunged.

Figure 2. The impact of COVID-19 on the Stock markets

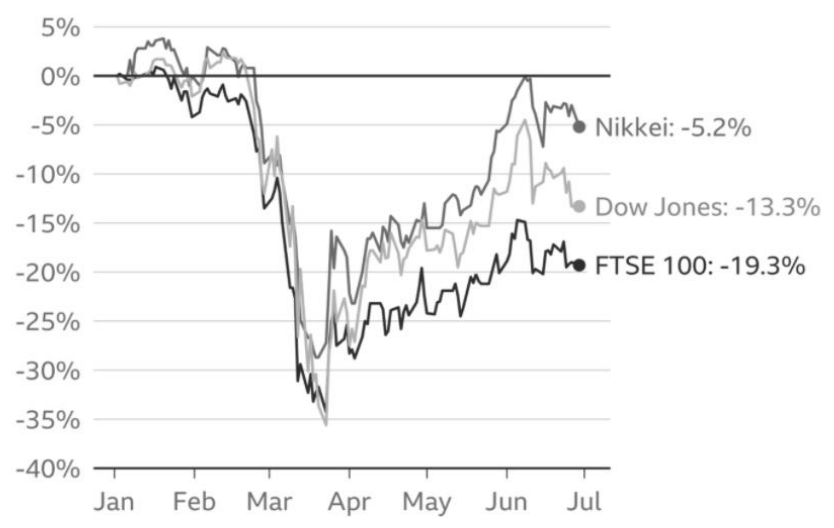

Source: 4, Lora Jones, Palumbo and Brown 2020 
In such situation, management is under high pressure not only from the economic implications but as well from the social, political and technological factors. Revenue streams in many industries declined dramatically e.g. "Communications Media and entertainment" and "Gas \& Oil". Widely used as a marker Brent crude oil price dropped with more than $50 \%$ in the beginning of the crisis (5, Maria Nicola et all, June 2020) or (6, Amadeo November 2020); in the next months the price recovered with around $30 \%$ but it is still historically low, based on the decreased demand and macroeconomic situation. Other sectors were completely blocked, like "Travel \& Transportation". In this sector was reported dramatic decrease of 58\%-78\% which measures international tourist arrivals (7, Borko 2020). One of the biggest carriers Lufthansa and Air France/KLM reported year-over-year revenue slump of respectively 89\% and $82 \%$ (7, Borko 2020). Food industry and Grocery needed to take a move toward digital, and supplying their goods to the front door of the customer. IT was challenged to provide quick and scalable solutions to many companies, markets and industries which was not an easy task.

The management layer of the companies needed to cope with their own challenges and problems and take quick decision based on limited information within quick timelines. In the analysis below, we will focus on two main management topics: Business operations and Human Resources management.

\section{a. Operations management}

The job of operations management (OM) consists of all the activities involved in transforming a product components or activities into a finished product or services. In addition, operations managers are involved in planning and controlling the systems that produce goods and services (8, J. Skripak 2016).

The following study will look specifically into IT sector represented by the following global companies: Alphabet, Cognizant, GoDaddy, Twitter, Zoom, DxC, IBM, HPE, HP Inc and ServiceNow.

As per provided definition, Operations Management might be a very broad term overseeing very wide range of activities; the study will focus on seven factors which clearly comes as consequence after COVID-19, and which impacts companies operations: 1) "Remote work and modified Schedules", 2) "Customer Accommodation", 3) "Health \& Safety", 4) "Supply chain impacts", 5) "Closed Stores and suspended services", 6) "Community Services", 7) "Layoffs". Below are listed the definitions provided by JustCaptal Global tracker (9, JustReport 2020):

1) "Remote work and modified Schedules" - Company is voluntarily shifting its nonessential employees to a remote work or work-from-home arrangement in response to the pandemic or are enacting alternative scheduling practices.

2) "Customer Accommodation" - Company is offering special accommodations to customers. Drill down to explore whether companies are offering discounts or price cuts to their customers, allowing customers to defer payment of goods and services, continuing to provide essential utilities to customers who are unable to make payments at this time, and/or providing services to vulnerable populations such as reserving the first hour of shopping for high-risk customers.

3) "Health \& Safety" - Company announced added health and safety measures during the pandemic to protect workers and customers alike.

4) "Supply chain impact" - Company has announced information about impacts or adjustments to its supply chain, including whether there have been job cuts, or the company has made a commitment to maintain business. 
5) "Closed Stores and suspended services" - Company is voluntarily closing some or all its retail or branch locations or suspending some or all its operations or services.

6) "Community Services" - Company is providing direct in-person or in-kind community services to help with relief efforts, such as organizing food banks, blood drives, or even providing free software for schools.

7) "Layoffs" - Company announced layoffs in order to offset lost revenues.

Chosen ten Global IT companies represents significant part of the industry and can be taken as stable marker showing the impact and actions. The table below gives their answers regarding the seven factors they take into account and where they have taken actions.

Table 1. COVID-19 responses of selected IT Global companies

\begin{tabular}{|c|c|c|c|c|c|c|c|c|c|c|}
\hline & 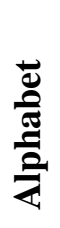 & 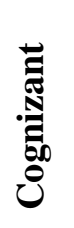 & 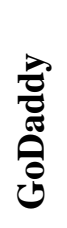 & 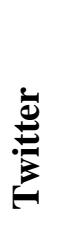 & 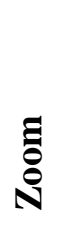 & Ŭ & $\sum_{\text {蒏 }}$ & 空 & 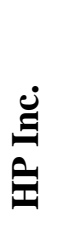 & \\
\hline $\begin{array}{l}\text { 1) Remote work and } \\
\text { modified Schedules }\end{array}$ & $\mathrm{x}$ & $\mathrm{x}$ & $\mathrm{x}$ & $\mathrm{x}$ & $\mathrm{x}$ & $\mathrm{x}$ & $\mathrm{x}$ & $\mathrm{x}$ & $\mathrm{x}$ & $\mathrm{x}$ \\
\hline 2) Customer accommodation & $x$ & & $x$ & & $\mathrm{x}$ & $\mathrm{x}$ & $x$ & $x$ & $x$ & $x$ \\
\hline 3) Health and safety & $\mathrm{x}$ & & & & & & & & & \\
\hline 4) Supply chain impacts & $\mathrm{x}$ & & & $\mathrm{x}$ & & $\mathrm{x}$ & $\mathrm{x}$ & $\mathrm{x}$ & $\mathrm{x}$ & $\mathrm{x}$ \\
\hline $\begin{array}{l}\text { 5) Closed stores and } \\
\text { suspended services }\end{array}$ & & & & & & & & $\mathrm{x}$ & $\mathrm{x}$ & $\mathrm{x}$ \\
\hline 6) Community services & $\mathrm{x}$ & $\mathrm{x}$ & & $\mathrm{X}$ & & & $\mathrm{x}$ & $\mathrm{x}$ & $\mathrm{x}$ & \\
\hline 7) Layoffs & & & & & & $\mathrm{x}$ & $\mathrm{x}$ & & & \\
\hline
\end{tabular}

Source: 9, JustReport 2020

With $100 \%$ answers, all selected companies choose to move towards remote way of work, which is expected, as this industry has all needed tools, knowledge and processes. Moreover, many of IT companies have already established practices and policies around remote workers.

The second answer where majority of the companies reported as impacting is "Customer accommodation" with $80 \%$. This shows that customer focus, flexibility and willingness are considered a priority for the sector. This is not a surprise as the companies are service providers and they have impacted clients in a way that they should react and adopt the situation.

"Supply chain impact" is the third impacting category with $70 \%$ answers that this is a factor that have impact on their operations. COVID-19 impacted travel and transportation industry all around the globe as well as row materials industry, and their supply due to the imposed lockdowns. Impact on the corporate value chain materialized in delayed production and shipments (10, Sallomi 2020).

The remaining three factors "5) Closed stores and suspended services", "7) Layoffs" and "3) Health and safety" are considered with minor impact on IT Companies business operations due to the respective low rate answers - respectively $30 \%, 20 \%$ and $10 \%$. Even with low response rate, these three factors should not be ignored as they have impact directly on companies' clients or on their employees and respectively on the quality of product/service, customer satisfaction and (not on the last place) direct impact on the employees. 
The last factor which will be reviewed, and which has direct impact on every IT company operations is "Business Continuity Planning" or BCP. Every global IT company need to have BCP in place, it needs to be practiced and adopted / updated regularly, which ensures its smooth and timely operations. Another angle is adopting company`s technology stack to the BCP, which needs to be scalable and flexible enough to address the respective situation and needs (10, Sallomi 2020). In global pandemic situation all of the included companies have implemented stringent BCP strategies (9, JustReport 2020) which clearly helped them in the quick reaction and proper answer.

\section{b. Human Resources Management}

Human resource management is one of the key pillars in companies strategic and overall management. This is even more valid for IT companies, no matter if they are small Software Development houses with 10-100 employees, medium size companies who has couple of thousands or big global players having from tens thousands to more than one hundred thousand employees. Human capital is a key for companies' success and so-called total cost of workforce or TCOW accounts for big part of their cost structure. COVID-19 put extreme pressure on the people around the globe, which affected how business operates and approaches their human resources. HR processes and procedures needed to be adopted to the "new reality" which impacted their productivity, efficiency, motivation and engagement.

In the literature there are different HR management models (11, Armstrong and Tailor 2020). Beer et al (12, Beer at al 1984) structured framework which is now known as 'Harvard framework' where HRM 'involves all management decision and actions that affect the nature of the relationship between the organization and employees'. There are two characteristics: 1) Direct managers are responsible and they ensure alignment between company strategy and HR policies, and 2) HR sets the policies and model how HR activities are developed and implemented.

There is as well '5-P model' (13, Schuler 1992) where the author describes five topics where HRM operates: 1) HP philosophy, 2) HR Policies, 3) HR Programs, 4) HR Practices and 5) HR Processes.

The third model which we will review is so called 'European Model' (14, Brewster and Larsen 1992), which has the following logic: 1) Environment, 2) Objectives, 3) Focus, 4) Relationship with employees, 5) relationship with direct managers and 6) Role of HR.

It can be summarized by the reviewed models that there are two main drivers that play key roles in HRM, especially in the pandemic situation:

1. HR Processes \& Policies,

2. Role of Direct Managers.

Relating back to the study shown in table 1, it is clear that all examined companies modified their work processes and policies moving towards 'work from home' or 'flexible models'. This is not an easy task as every country has its own legal framework and required process and policies adoption from HR departments. Then the implementation passed though leadership and direct management that needs to communicate, implement, execute and monitor how this affects their employees in all aspects as: efficiency, motivation, engagement and so on. The other main factor which affects HRM is "Supply chain" effects which $70 \%$ of the companies think it was impacted. Here there are different factors starting from un-availability to deliver 
the services / products, issues with performing their daily tasks and facing direct problems related to the clients.

At the beginning of the pandemic, companies took fast decisions without knowing how this will impact their operations and results, and during the course of the year they all started to analyze different data to see how these actions actually affect them. In his paper Paulo et al [15] shows how COVID-19 impacts outcome for software developers:

Figure 3. Summary of the survey results on the impact of COVID-19 on task completion time, productivity, and quality of the work

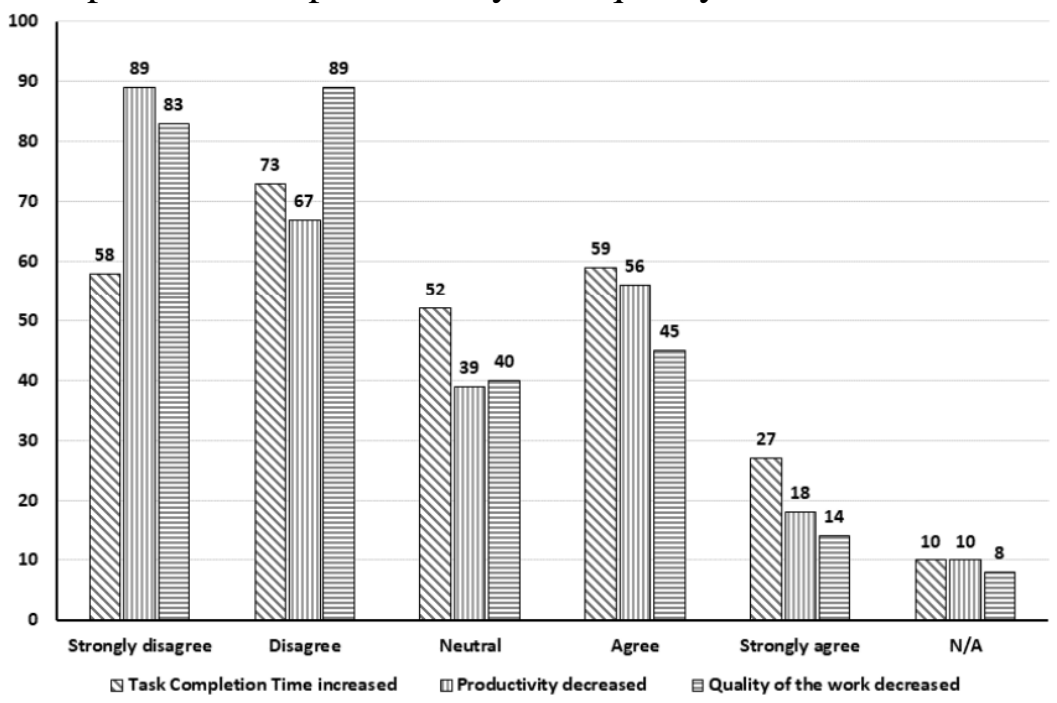

Source: 15, Paolo Anselmo et al, August 2020

This leads to an important conclusion that flexible work schedule and work from home don't impact their quality of work and productivity. The summarized result of the survey (Paolo Anselmo et al, August 2020) is shown in figure 4.

Figure 4. COVID-19 impact on software developers

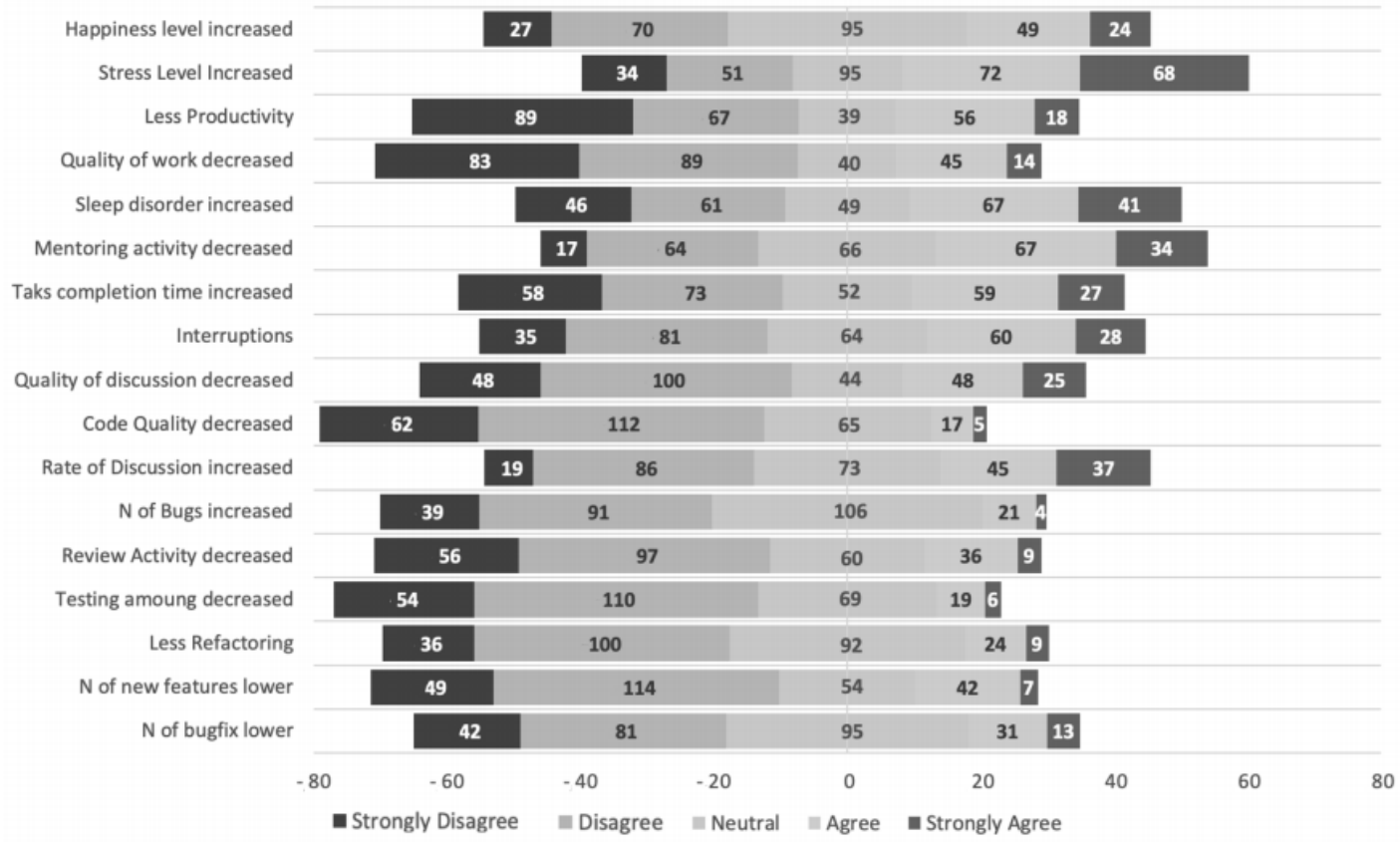

Source: 15, Paolo Anselmo et al, August 2020 


\section{Conclusion}

Based on the above study, we can conclude that Corporate Management, as well as Human Resource Management, reacted fast and unedified to the global pandemic. They joined their forces and acted with great flexibility by:

- Adopting processes,

- Changing HR policies,

- Modifying their approach to Customers,

- Raised the level of safety,

- Adopting their value and supply chains.

The companies who focused on these factors stayed and became even more relevant for their clients and were able to increase customer and employee satisfaction. That is why the next steps will be bringing: 1) Measuring, 2) Analyze, 3) Change, 4) Adopt, and 5) Maintain of the newly implemented practices and processes, where actually data analytics will come to play. All of these factors can be monitored and analyzed no matter of the size of the company and its industry. However, Global IT companies have strategic advantages as: Infrastructure (Software and Hardware), Skill-full employees, Data Driven culture, which gives them flystart and moreover position them better compared to the other industries where processes are slow, where companies don't have the needed infrastructure and the employees are not keen into digitalization. We believe that analytical approach and data driven approach into handling situations like COVID-19 global pandemic will rise the bar and will push the companies more towards digitalization and automation, as it gives enormous level of flexibility and adoptability as well as quick resolution to problems which they have never faced before.

\section{References}

[1] WHO publishes interactive timeline of its response. July 2020. Rolling updates on coronavirus disease (COVID-19). Retrieved from https://www.who.int/emergencies/diseases/novel-coronavirus-2019/events-as-theyhappen

[2] World Health organization web site statistics. Retrieved from https://www.who.int/news/item/29-06-2020-covidtimeline

[3] Thomas H. Davenport. 2013. "Analytics 3.0", Harvard business review 2013. Retrieved from https://hbr.org/2013/12/analytics-30

[4] Lora Jones, Daniele Palumbo and David Brown Coronavirus, "A visual guide to the economic impact". BBC June 2020. Retrieved from https://www.bbc.com/news/business-51706225

[5] Maria Nicola, Zaid Alsafi, Catrin Sohrabi, Ahmed Kerwan, Ahmed Al-Jabir, Christos Iosifidis, Maliha Agha, and Riaz Aghaf, "The socio-economic implications of the coronavirus pandemic (COVID-19): A review". June 2020. Retrieved from https://www.ncbi.nlm.nih.gov/pmc/articles/PMC7162753/

[6] KIMBERLY AMADEO, "Oil Price History-Highs and Lows Since 1970". November 2020. Retrieved from https://www.thebalance.com/oil-price-history-3306200

[7] Seth Borko, Wouter Greets, Haixia Wang, "The travel industry turned upside down: Insights, analysis, and actions for travel executives". September 2020. Retrieved from https://www.mckinsey.com/industries/travel-logistics-and-infrastructure/ourinsights/the-travel-industry-turned-upside-down-insights-analysis-and-actions-fortravel-executives 
[8] Stephen J. Skripak, Richard Parsons, Anastasia Cortes, Anita Walz, "Operations Management". Pamplin College of Business and Virginia Tech Libraries. July 2016 p.1213

[9] JustReport. “The COVID-19 Corporate Response Tracker”. JustCapital, November 2020. Retrieved from https://justcapital.com/reports/the-covid-19-corporate-response-trackerhow-americas-largest-employers-are-treating-stakeholders-amid-the-coronaviruscrisis/\#methodology

[10] Paul Sallomi, "Understanding the impact of COVID-19 Technology Sector". Deloitte, April 2020. Retrieved from https://www2.deloitte.com/global/en/pages/aboutdeloitte/articles/the-heart-of-resilient-leadership.html

[11] Michael Armstrong and Stephen Taylor, "Armstrong`s Handbook of Human Resources Management Practice", $15^{\text {th }}$ edition, Kogan Page 2020 pp.10-14

[12] Michael Beer, Bert Spector, Paul R. Lawrence, D. Quinn Mills, Richard E. Walton, "Managing Human Assets". The free press, November 1984

[13] Schuler, R.S., Strategic Human Resource Management: "Linking People with the Needs of Business. Organizational Dynamics", 1992 pp.18-32

[14] Brewster, C., \& Larsen, H. H., "Human resource management in Europe": evidence from ten countries", International Journal of Human Resource Management, 1992 409-434

[15] Paulo Anselmo da Mota Silveira Neto, Umme Ayda Mannan, Eduardo Santana de Almeida, Nachiappan Nagappan, David Lo, Pavneet Singh Kochhar, Cuiyun Gao, Iftekhar Ahmed, "A Deep Dive on the Impact of COVID-19 in Software Development", Aug. 2020 